use the Mental Health Act because it would stigmatise the child concerned.

original papers
Stigma associated with the use of the Mental Health Act

Many respondents commented on the stigmatising effect of using the Mental Health Act, and the possible subsequent consequences for the individual concerned. Some mentioned specific consequences, such as difficulty of obtaining a visa for travel to the US. For some, fear of stigma led to a reluctance to use the Mental Health Act, and one described its use in those under the age of 18 as 'unethical'.

\section{Conclusion}

From this survey a range of themes has been identified, and these have informed the design of subsequent data collection tools. This includes a questionnaire for child and adolescent in-patient psychiatrists, to ascertain their knowledge, attitude and practice with regard to the use of legislation. Data collected from this and other commponents of CAMHA-CAPS will address many of these issues. Preliminary findings from this study were submitted to the Department of Health for consideration, prior to the drafting of the new Mental Health Act.

\section{References}

NHS HEALTH ADVISORY SERVICE (1996) WORRALL, A. \& O'HERLIHY, A. (2001) Child and Adolescent Service. Safeguards for Young Minds: Young People and Protective Legislation. Psychiatrists' views of in-patient child and adolescent mental health services: a survey of members of the child and adolescent faculty of the College. Psychiatric Bulletin, 25, 219-222.

Alex Mears (PhD) ResearchWorker, Adrian Worrall Project Manager, College Research Unit, 83 Victoria Street, London SW1H OHW

\title{
Learning styles of psychiatrists and other specialists
}

\author{
AIMS AND METHOD \\ To describe how the Learning Styles \\ Inventory was used to assess the pre- \\ ferred learning styles of a group of \\ senior and specialist registrars from \\ different specialities attending a \\ management course.
}

\author{
RESULTS \\ Of the 272 doctors studied, the \\ learning styles of psychiatrists \\ $(n=42)$ emerged as significantly dif- \\ ferent to the group as a whole, \\ favouring reflective observation and \\ concrete experience rather than \\ active experimentation or abstract \\ conceptualisation.
}

\begin{abstract}
CLINICAL IMPLICATIONS
Knowledge of learning styles can help improve interactions with other specialities that adopt different learning strategies, and assist with the individual psychiatrist's lifelong learning. To engage the interest of medical students, psychiatrists may need to consider different teaching approaches in line with the prevalent learning style.
\end{abstract}

Doctors spend much of their time learning. When they qualify they may have spent nearly 20 years in full-time education. They will have been tested at various stages and become used to the idea of acquiring the knowledge that examiners expect of them. Learning, however, continues, both in the acquisition of skills needed in the clinical area and the facts needed to satisfy higher professional examiners. Doctors are almost unique among other professional groups in the number of examinations they sit and with the emergence of clinical governance there is an added weight placed upon lifelong learning. So, doctors need to continue learning. A better understanding of the way in which they learn must be valuable.

The business world has been interested in the idea of learning styles since the Second World War, with the Learning Styles Inventory devised by Kolb et al (1984) being the most widely-used tool. Although formulated to study organisational behaviour in the business environment, it is equally applicable to medical practitioners, both for doctors in training (Gatrell \& White, 1999) and as a reflective tool used by experienced consultants (Brigden, 1999).

Kolb et al postulate learning as a four-stage cycle (see Fig. 1). The individual has experiences upon which he or she reflects and makes observations. These are then used to form concepts and generalisations. Experimental actions follow and these, in their turn, create new experiences. The Learning Styles Inventory described by Kolb et al (1984) measures individual strengths and weaknesses of the learner in these four stages (or modes) of the learning process. It is a simple selfdescription test that has nine sets of four descriptions with the respondent marking words that are most, through to least, like him- or herself. This then generates two axes, one being active experimentation (AE) $v$. reflective observation ( $R O)$, the other being concrete experience (CE) v. abstract conceptualisation (AC). These axes are then plotted out to give the four learning styles described in Fig. 1. For example, one set of four words is 


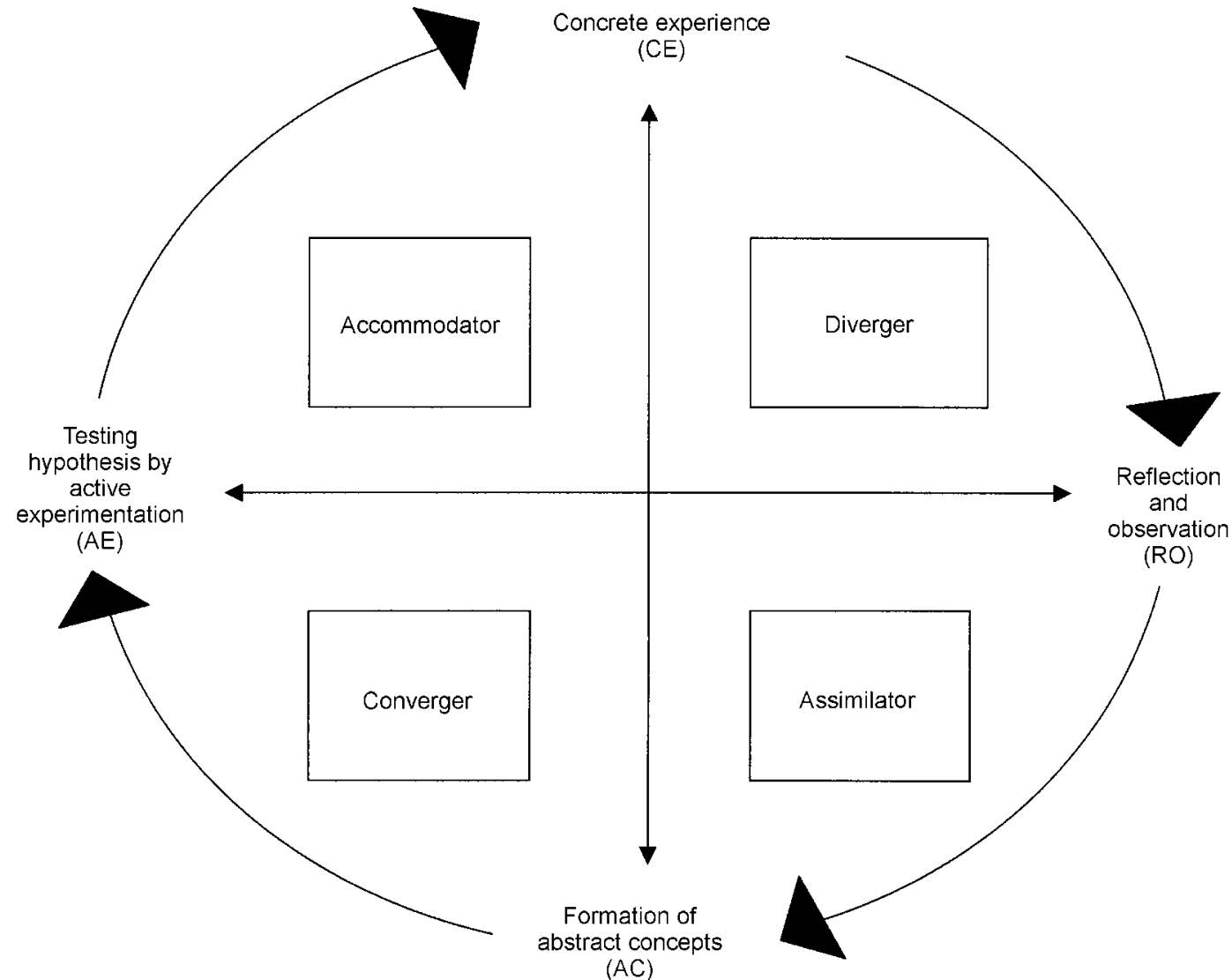

Fig. 1. Learning as a four stage cycle, with the four learning styles: converger, diverger, assimilator and accommodator

Converger: knowledge focused on specific problems. Use abstract conceptualisation and active experimentation in problem solving, decision-making and the practical application of ideas. Prefer to deal with technical tasks rather than social and interpersonal issues. Style characteristic of engineers and technical specialists.

Diverger: opposite strengths to the converger, emphasises concrete experience and reflective observations. View situations from many perspectives and organise relationships into a meaningful 'gestalt'. Style characteristic of counsellors and personnel managers.

Assimilator: by combining abstract conceptualisation and reflective observations are able to create theoretical models and assimilate observations into an integrated explanation. Style characteristic of mathematicians and those in research and planning departments.

Accommodator: opposite strengths to the assimilator, emphasises concrete experience and active experimentation. Intuitive trial and error approach; action orientated and adapt well to changing circumstances. Style characteristic of business world, especially marketing and sales. Based on Kolb et al. 1984.

'feeling, watching, thinking and doing', which reflect $C E$, $R O, A C$ and $A E$, respectively.

\section{The study}

Senior and specialist registrars of all specialities working in the South and West Region are encouraged to attend the 6-day management course organised locally by the Postgraduate Dean. Selection bias is unlikely to be an issue because all trainees are expected to attend a management course. The majority of doctors elect to attend this particular course. Over the past 4 years 272 such doctors have attended the course and as part of the programme have completed the Learning Styles Inventory, as described above.

The nine questions and scoring instructions were distributed to the participants, who then completed and scored their responses. The results were plotted and individual learning styles recorded by the course organiser.

\section{Findings}

Table 1 shows the higher professional trainees divided by speciality and the number within each professional group recording each of the four types of learning style. Half scores are possible where the individual fell exactly on the dividing line between two different styles. It can be seen that all specialities, except psychiatry, have convergence as the most numerous category. Psychiatrists' learning styles were more evenly spread, the most numerous category being divergers at $32 \%$ of the total. The data were further analysed by separating the scores according to the two axes described above, axis one being $A E$ as opposed to RO with axis two being CE as opposed to AC (Table 2). If the results of psychiatrists are compared with the pooled results of all the specialities collectively, there is a significant difference in scores on both these scales. Generally the whole sample favours $A E$, with psychiatry split more evenly between this and RO $(P=0.03)$. Differences are even more marked in axis two with specialist/ senior registrars in general favouring $A C$ while those from 
Table 1. Learning styles of the different specialities

original

papers

$n$ in each learning style (\% of each row)

\begin{tabular}{|c|c|c|c|c|c|}
\hline Speciality & Convergence & Divergence & Assimilation & Accommodation & Total \\
\hline Medicine & $16 \quad(50)$ & $6 \quad(19)$ & $6 \quad(19)$ & $4 \quad(13)$ & 32 \\
\hline Anaesthetics & $21.5(58)$ & $5.5(15)$ & $2.5 \quad(7)$ & $7.5(20)$ & 37 \\
\hline Psychiatry & $9 \quad(21)$ & $13.5(32)$ & $8.5(20)$ & $11 \quad(26)$ & 42 \\
\hline Paediatrics & $14.5(39)$ & $8 \quad(22)$ & $4.5(12)$ & $10 \quad(27)$ & 37 \\
\hline Total & $129 \quad(47)$ & $48 \quad(18)$ & $43.5(16)$ & $51.5(19)$ & 272 \\
\hline
\end{tabular}

Table 2. The two axes of learning style: psychiatrists and surgeons compared to the group as a whole

\begin{tabular}{|c|c|c|c|c|c|c|c|}
\hline \multirow[b]{2}{*}{ Axis one } & \multirow[b]{2}{*}{ Active experimentation (as opposed to reflective observation) } & \multicolumn{2}{|c|}{ Surgery $n=62$} & \multicolumn{2}{|c|}{ All $n=272$} & \multicolumn{2}{|c|}{ Psychiatry $n=42$} \\
\hline & & $50^{*}$ & $81 \%$ & 180.5 & $66 \%$ & $20^{*}$ & $48 \%$ \\
\hline Axis two & Abstract conceptualisation (as opposed to concrete experience) & $51 * *$ & $82 \%$ & 172.5 & $63 \%$ & $17.5^{* *}$ & $42 \%$ \\
\hline \multicolumn{8}{|c|}{${ }^{*} P<0.05 . * * P<0.01$} \\
\hline \multicolumn{8}{|c|}{ All probabilities calculated using $\chi^{2}$ tables. } \\
\hline
\end{tabular}

psychiatry favour $C E(P=0.01)$. For surgeons, there is also significant variation in their scoring on both scales $(P=0.03,0.01)$ and it is in the opposite direction to psychiatrists. The two modes that contribute to the converger style ( $A E$ and $A C$ ) are more prevalent in surgeons when compared to the group as a whole and less prevalent in psychiatrists. All probabilities were calculated using $\chi^{2}$ tables.

\section{Comments}

The 'popularity' of convergers in the medical profession has been demonstrated in research on surgical trainees (Drew et al, 1998), paediatricians (Kosower, 1995) and medical students (Lynch et al, 1998). The results suggest that psychiatrists approach learning and problem solving in a different way to other doctors in general and surgeons in particular. This has a number of implications.

First, in the liaison psychiatry setting the psychiatrist may approach a clinical problem in a very different way to the other specialists involved. Convergers seem to work best when there is a single correct answer or solution to a question or problem, as can be seen with surgeons. Divergers can organise many relationships into one meaningful 'gestalt', an invaluable approach for a psychiatrist. It is to be imagined that this could potentially create conflict between specialities over patient management, and it is known that nonpsychiatric doctors view the psychiatric consultation in a very different way to the psychiatrist (Cohen-Cole, 1982)

Second, it is known that medical students commonly have a negative view of psychiatry, regarding the speciality as unscientific, different from medicine generally and not using medical skills (Creed \& Goldberg, 1987). The work of Lynch et al (1998) showed that in a sample of medical students, $45 \%$ were convergers, $26 \%$ assimila- tors, $21 \%$ accommodators and only $8 \%$ were divergers. So, for example, $66 \%$ of students are convergers or accommodators and are thus drawn to AE. Psychiatrists are less likely to espouse this stage of the learning process and may approach teaching in a way that dwells on reflective observation, their preferred approach. This is unlikely to be a style that would engage the majority of medical students, and would help to explain the students' negative views of psychiatry. A consideration of this may help engage students with the speciality - both to have a more favourable attitude generally and to consider it as a career.

Third, among all doctors, including those who have chosen psychiatry as a career, there is a need to consider lifelong learning. Using a learning portfolio is one approach to this that helps keep the individual interested and engaged (Brigden, 1999). This exercise in reflecting on experience and future objectives can be expressed in terms of different quadrants of the learning cycle. The individual's knowledge of his or her own learning style helps inform this process, helps people to understand why they find some forms of learning more acceptable than others and helps people take full advantage of learning opportunities as they arise (Gatrell \& White, 1999).

Finally, it is worth remembering that Kolb et al (1984) suggest that to become a more effective learner one needs to develop competencies in all learning styles. The key to effective learning is to be competent in each mode where appropriate.

\section{References}

BRIGDEN, D. (1999) Constructing a learning portfolio (career focus). BMJ, 319,2

COHEN-COLE, S. A. \& FRIEDMAN, C. P. (1982) Attitudes of non-psychiatric physicians towards psychiatric consultations. Hospital and Community Psychiatry, 33, 1002-1005

CREED, F. \& GOLDBERG, D. (1987)

Students' attitudes towards psychiatry. Medical Education, 21, 227-234. 
DREW, P. J., CULE, N., GOUGH, M., et al KOLB, D. A., RUBIN, I. M. \& MCINTYRE, (1998) Optimal education techniques J. M. (1984) Organizational Psychology. for basic surgical trainees: lessons from An Experiential Approach to education theory. Journal of the Royal Organizational Behaviour (4th edn) College of Surgeons of Edinburgh, 44, Englewood Cliffs: Prentice-Hall. 55-56.

GATRELL, J. \& WHITE,T. (1999) The Specialist Registrar Handbook. Oxford: KOSOWER, E. (1995) Is there a generalist learning style? Academic Medicine, 70, 745-746.
LYNCH,T. G., WOELFL, N. N., STEELE,

D. J., et al (1998) Learning style

performance. American Journal of

Surgery, 176, 62-66.
唡

original

papers

Nicholas Airey Specialist Registrar in Adult Psychiatry,

James Marriott Medical Audit Facilitator, Somerset Partnership NHS \& Social

CareTrust, Beech Court, BridgwaterTA6 3LS, June Rodd Management

Development Consultant, Coombe House, Stoke Hill, Chew Stoke, Bristol BS18 8XF 